\title{
Modulation of Cough Reflex by Gaba-Ergic Inhibition in Medullary Raphé of the Cat
}

\author{
Lukas MARTVON ${ }^{1}$, Zuzana KOTMANOVA ${ }^{\mathbf{1}}$, Boris DOBROLUBOV ${ }^{1}$, Lucia BABALOVA ${ }^{\mathbf{1}}$, \\ Michal SIMERA ${ }^{1}$, Marcel VETERNIK ${ }^{1}$, Teresa PITTS ${ }^{2}$, Jan JAKUS ${ }^{1}$, Ivan POLIACEK ${ }^{1}$ \\ ${ }^{1}$ Institute of Medical Biophysics, Jessenius Faculty of Medicine in Martin, Comenius University \\ Bratislava, Martin, Slovakia, ${ }^{2}$ Department of Neurological Surgery, Kentucky Spinal Cord Injury \\ Research Center, University of Louisville, Louisville, USA
}

Received July 15, 2019

Accepted September 9, 2019

\section{Summary}

We studied the effects of GABA receptor agonists microinjections in medullary raphé on the mechanically induced tracheobronchial cough response in anesthetized, unparalyzed, spontaneously breathing cats. The results suggest that GABA-ergic inhibition significantly contributes to the regulation of cough reflex by action of both $G_{A B A}$ and $G A B A_{B}$ receptors. The data are consistent with inhomogeneous occurrence of GABA-ergic neurons in medullary raphé and their different involvement in the cough reflex control. Cells within rostral nucleus raphé obscurus with dominant role of $\mathrm{GABA}_{A}$ receptors and neurons of rostral nucleus raphé pallidus and caudal nucleus raphé magnus with dominant role of $\mathrm{GABA}_{\mathrm{B}}$ receptors participate in regulation of cough expiratory efforts. These cough control elements are distinct from cough gating mechanism. GABA-ergic inhibition in the raphé caudal to obex had insignificant effect on cough. Contradictory findings for GABA, muscimol and baclofen administration in medullary raphé suggest involvement of coordinated activity of GABA on multiple receptors affecting raphé neurons and/or the local neuronal circuits in the raphé modulating cough motor drive.

\section{Key words}

Cough • Microinjection • Medullary raphé • Baclofen • Muscimol

\section{Corresponding author}

Ivan Poliaček, Institute of Medical Biophysics, Jessenius Faculty of Medicine in Martin, Comenius University in Bratislava, Malá Hora 4, 03601 Martin, Slovak Republic. E-mail: Ivan.Poliacek@jfmed.uniba.sk

\section{Introduction}

Caudal raphé, that spreads over the medullary midline, consists of three neuronal populations: nucleus raphé obscurus (NRO), nucleus raphé pallidus (NRP), and the nucleus raphé magnus (NRM) (Pritchard and Alloway 1999, Taber et al. 1960). Rostral raphé is comprised of nucleus raphé pontis, nucleus centralis inferior, nucleus centralis superior a nucleus raphé dorsalis (Pritchard and Alloway 1999, Taber et al. 1960). Brainstem rapheal reticular formation represents complex assembly of functional neuronal mediators, with their own inherent characteristics (Lindsey et al. 1994, Ptak et al. 2009). Rapheal neurons project to many CNS regions, with serotonin-ergic neurons being most prevalent, representing $15 \%$ of total neurons in the caudal raphé (Hornung 2003). Rapheal nuclei of medulla oblongata are significantly engaged in multiple respiratory processes, including breathing, coughing and other respiratory reflexes (Aoki et al. 1995, Baekey et al. 2003, Budzinska and Romaniuk 1995, Miller et al. 1996, Jakus et al. 1998, Lindsey et al. 1992, Sessle et al. 1981, Shannon et al. 2004).

Rapheal neuron spiking patterns and their substantial role in cough reflex (Baekey et al. 2003, Jakus et al. 1998), suggested their potential participation in cough gating mechanism - the excitatory neuronal population driving the cough response (Bolser and Davenport 2002, Bolser et al. 2006). However, cough gating is also sensitive to codeine, but previously, we have observed limited effects of direct codeine 
microinjections (Poliacek et al. 2012), even though many of rostral rapheal neurons express $\mu$-opioid receptors (Dias et al. 2012). Other pharmaceutical agents such as kainic acid, which produces a functional lesion, caused reduction or elimination of cough in the rabbit (Simera et al. 2013) and cats (Jakus et al. 1998).

We hypothesized that microinjections of GABA receptor agonists in medullary raphé would result in decreased cough response elicited from mechanical stimulation of tracheobronchial mucosa in cats. Based on our previous results we also expected changes in the temporal characteristics of cough motor pattern, likely with regional differences.

\section{Methods}

The experiments were carried out on 31 cats $(4 \circ, 27 \hat{\jmath}, 3.82 \pm 0.13 \mathrm{~kg})$. The animals were unparalyzed, spontaneously breathing and anesthetized with sodium pentobarbital (Pfannenschmidt $\mathrm{GmbH}$; initial dose $38 \mathrm{mg} / \mathrm{kg}$, i.p., 1-3 mg/kg i.v. supplementary as needed). At the beginning of the experiment, atropine (Biotika; $0.15 \mathrm{mg} / \mathrm{kg}$, i.v.) was administered to reduce the mucosal secretion in the airways and hydrocortisone (VUAB Pharma a.s.; $2 \mathrm{mg} / \mathrm{kg}$, i.v.) to reduce brain swelling. The level of anesthesia was assessed regularly by the absence of reflex withdrawal of the hind limb in response to noxious pinching of the paw and the presence of palpebral reflex and jaw tone. The cats were breathing spontaneously oxygen-enriched air (30-40\% of $\left.\mathrm{O}_{2}\right)$. The trachea, femoral vein and artery were cannulated. During the experiments respiratory rate (RR), end-tidal $\mathrm{CO}_{2}$ concentration $\left(\mathrm{ETCO}_{2}\right)$, arterial blood pressure, and rectal temperature were continuously monitored. The animal's temperature was maintained within the range 37.5$38.5^{\circ} \mathrm{C}$ using a heating pad and a lamp. The samples of arterial blood were removed periodically to perform blood gas and $\mathrm{pH}$ analysis. For the measurement of intrathoracic pressure (esophageal pressure, EP) a soft balloon was inserted into the esophagus. The electromyograms (EMG) were recorded by bipolar insulated wire hook electrodes bilaterally from the diaphragm (DIA) and expiratory transversus abdominis and/or external oblique abdominal (ABD) muscles. In some animals DIA electrodes were placed percutaneously. We performed the occipital craniotomy and partial cerebellectomy while the animals were placed prone in a stereotaxic frame. Animal care as well as all procedures were performed in accordance with the
Animal Welfare Guidelines of the Comenius University and the legislation for animal use and welfare of Slovak Republic and European Union (Directive 2010/63/UE).

The cough reflex was elicited mechanically by a soft polyethylene stimulating fiber via tracheal cannula (tracheobronchial cough, TB). The mechanical stimulation was always performed by the same person, with the same stimulation pattern during the trials.
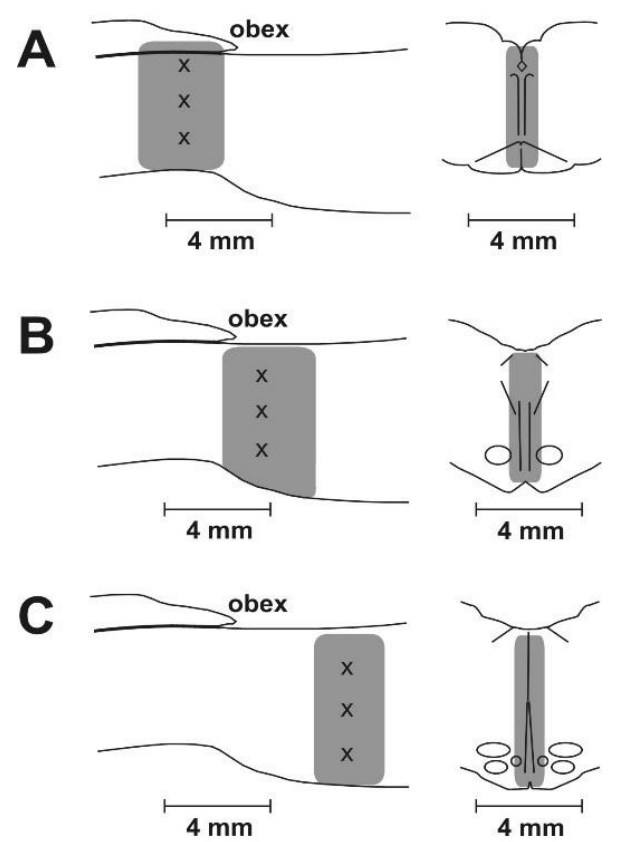

Fig. 1. Reconstruction of GABA microinjection sites in medullary raphé. Reconstruction of regions with presumed effective GABA concentration after microinjection $(X)$ and diffusion into medullary raphé nuclei (gray area). Medial plane reconstructions on the left, transversal planes on the right. Locations included the following: A) microinjections into caudal region, approximately $1.2 \mathrm{~mm}$ caudal to obex; B) microinjections into region, appoximately $1.8 \mathrm{~mm}$ rostral to obex; and C) microinjections into region, approximately $4 \mathrm{~mm}$ rostral to obex. In all analyzed animals, we confirmed the solution coverage of more than $40 \%$ of the maximal target area (highlighted), $80 \%$ in dorso-ventral and $70 \%$ in lateral and rostro-caudal direction. Reference points are as follows: obex, central canal of the spinal cord, medullary midline, rapheal nuclei, dorsal and ventral surface of the medulla, bottom of the $4^{\text {th }}$ ventricle.

The drugs: 1) GABA (1 mM, Sigma Aldrich, Co.); 2) a selective $\mathrm{GABA}_{\mathrm{A}}$ receptor agonist muscimol (0.5 mM, 2 mM in two animals, Sigma Aldrich, Co.); and 3) a selective $\mathrm{GABA}_{\mathrm{B}}$ receptor agonist baclofen $(1 \mathrm{mM}$, BIOTREND AG Zurich) were dissolved in artificial cerebrospinal fluid (aCSF, $\mathrm{pH}$ 7.3-7.4). Microinjections were performed in 3 rostro-caudal locations for GABA ( 2 microinjections in each location in 3 depth positions during 2 consecutive injection sequences, i.e. 6 microinjections in total; Fig. 1) and into 2 regions for muscimol and baclofen (total of 4 microinjections in 
2 rostro-caudal positions and 2 depth levels; Fig. 2). The position of micropipette tip for GABA microinjections (Fig. 1) caudal to obex was 1.2-1.0 mm caudal to obex, in the midline and the depth of 1.0-1.2, 2.1-2.3 and $3.2-3.5 \mathrm{~mm}$ under the dorsal medullary surface. The coordinates for rostral to obex microinjections (rostral to obex/lateral to midline/depth from the dorsal medullary surface) were $1-2.5 / 0 / 1-1.2 ; 2.1-2.3 ; 3.2-3.5 \mathrm{~mm}$. The coordinates for the most rostral microinjections were 4.0-4.3 / 0 / 1.1-1.2; 2.3-2.4; 3.4-3-6 mm (Fig. 1). Muscimol and baclofen microinjections were aimed dorso-caudally into NRO and rostro-ventrally into NRP and caudal NRM (Taber et al. 1960). Positioning of micropipette for dorso-caudal microinjections were 0.5 1.5 / 0 / 0.8-1.2; 1.8-2.4 mm and for rostro-ventral microinjections 3.5-4.5 / 0 / 3.0-3.3; 4.0-4.5 mm (Fig. 2). A single glass micropipette (tip diameter 16-60 $\mu \mathrm{m}$ ) was used for the pressure-injections. The volume of injectate was measured using microscope scale by monitoring the movement of the fluid meniscus in the pipette barrel. In

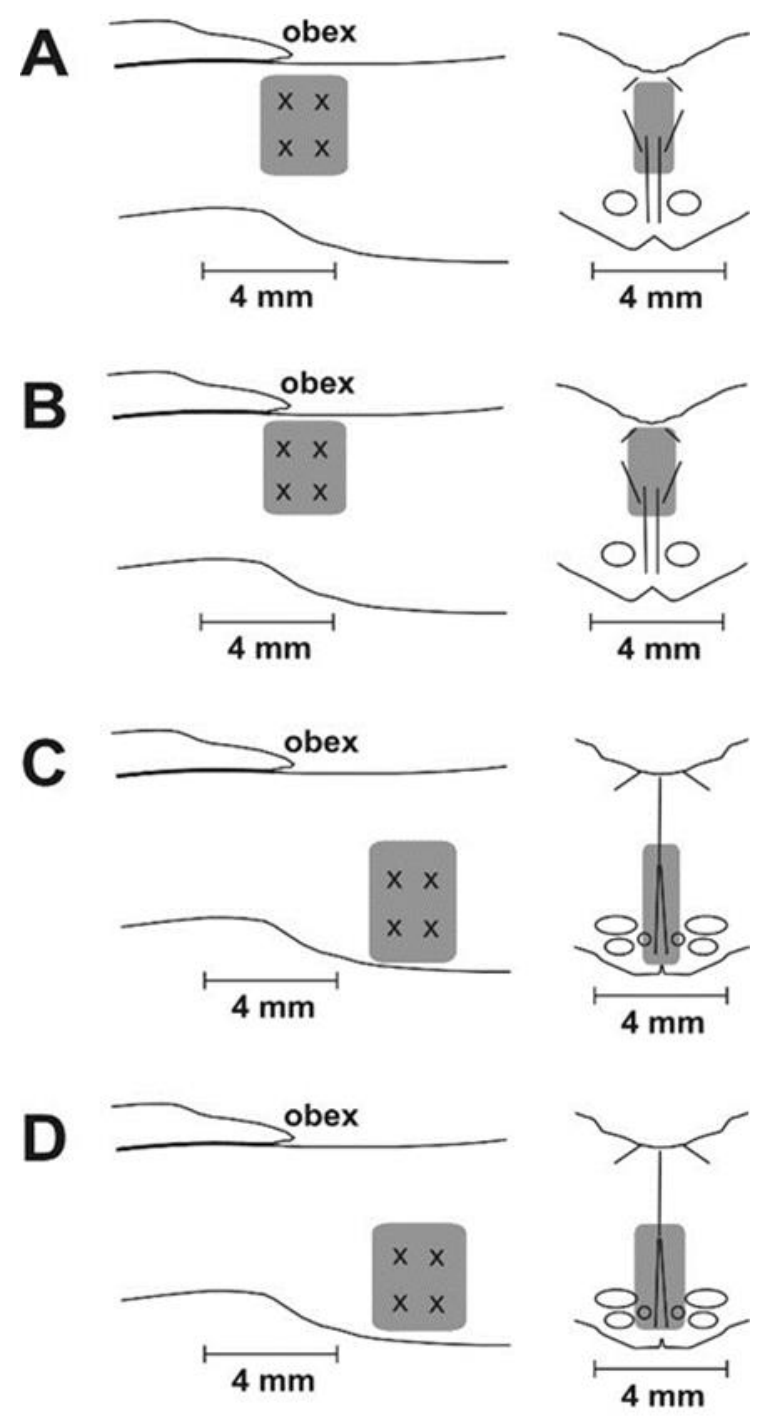

order to detect the microinjection sites all solutions contained fluorescent latex beads (Life Technologies Eugene, Oregon, USA).

For histological processing, the brainstem was removed, fixed in $4 \%$ paraformaldehyde and followed by a $30 \%$ sucrose solution. Transverse slices $100 \mu \mathrm{m}$ thick (cut using freezing microtome), were examined by light and fluorescent microscopy. The highest intensity of staining corresponds to the position of micropipette tip during microinjection. Due to multiple microinjections during each test we reconstructed the regions with presumably effective drug concentration (Fig. 1, 2). The exclusion criterion was a microinjection spot more than $0.3 \mathrm{~mm}$ from the target or insufficient medullary diffusion (Fig. 1, 2). The structures and coordinates are consistent with published data (Berman 1968) and our own adjustments (Poliacek et al. 2017). Control aCSF microinjections (and related analysis of data) were performed during our previous experiments (Poliacek et al. 2012, 2014).

Fig. 2. Reconstruction of muscimol and baclofen microinjection sites in medullary raphé. Reconstruction of regions with presumed effective concentration after microinjection $(X)$, and diffusion of muscimol and baclofen into medullary rapheal nuclei (gray area). Medial plane reconstructions on the left, transversal planes on the right. The locations were as follows: A) muscimol microinjections into dorso-caudal region, approximately 0.5 and $1.5 \mathrm{~mm}$ rostral to the obex; B) baclofen microinjections into dorso-caudal region, approximately 0.5 and $1.5 \mathrm{~mm}$ rostral to the obex; C) muscimol microinjections into rostro-ventral region, approximately 3.5 and $4.5 \mathrm{~mm}$ rostral to the obex; and D) baclofen microinjections into rostro-ventral region, approximately 3.5 and $4.5 \mathrm{~mm}$ rostral to the obex. In all analyzed animals, microinjections covered more than $50 \%$ of maximal highlighted volumes: $90 \%$ in dorso-ventral, $80 \%$ in rostro-caudal and $70 \%$ in lateral direction. Reference points are as follows: obex, central canal of the spinal cord, medullary midline, rapheal nuclei, dorsal and ventral surface of the medulla, bottom of the $4^{\text {th }}$ ventricle. 
All the EMGs were amplified, filtered (100$3000 \mathrm{~Hz}$; GRASS), digitized (12-bit multi-function plugin ISA card, Dataq Instruments, sampling frequency of 10 or $20 \mathrm{kHz}$ ), and recorded along with blood pressure and EP waveforms (Windaq, DATAQ Instruments, USA). EMGs were subsequently rectified and integrated moving average (Spike2 software, CED, Cambridge, England) with a time constant of $200 \mathrm{~ms}$ (Veternik et al. 2013). The number of cough efforts (CN) induced during the mechanical stimulation of trachea (the average $\mathrm{CN}$ per 10s duration stimulation trial), the DIA and ABD EMG's amplitudes (moving averages), and the amplitudes of EP during appropriate phases were analyzed. In the temporal analysis (as previously reported Poliacek et al. 2016), the duration of cough-related DIA (TDIA) and ABD (TABD) activations, augmenting part of DIA (CTI, inspiratory cough phase), the time from the maximum of DIA activity to the end of cough-related ABD activity (CTE1, active expiratory cough phase), the time from the maximum of DIA activity to the end of the cough cycle (CTE, cough expiratory phase), the time between maxima of DIA and ABD activity (peaks), the quiescent period of the cough cycle (cough TE2 phase, CTE2), the duration of all cough-related EMG activity (CTactive), and the whole cough cycle duration were analyzed in each stimulation period (CTtot). In the analysis of cardiorespiratory data, RR, respiratory phase durations - inspiratory, post-inspiratory, quiescent expiratory (TI, TE1, TE2), respiratory-related amplitudes of DIA and EP, heart rate (HR), mean blood pressure were measured during 3 standard consecutive breathing cycles. The measurement just before the $1^{\text {st }}$ microinjection and then within $1 \mathrm{~min}$ after the last microinjection in the protocol, if necessary, at about 7, 10-15 min postmicroinjections and in the recovery period (20-60 min post-injection) were accomplished. Blood gases and blood pH analysis (epoc Blood Analysis System, Siemens, CZ) was done in appropriate interval before and after microinjections and in the recovery period.

The results are expressed as means \pm SE. In statistical analysis repeated measures ANOVA, with Student-Newman-Keuls post-test, ordinary ANOVA, Friedman test or Kruskal-Wallis test with Dunn post-test and paired t-test or Wilcoxon matched-pairs test were applied as appropriate. The differences of variables were considered significant at $p<0.05$.

\section{Experimental protocol}

Approximately 20 cough stimulation trials separated by $1 \mathrm{~min}$, were executed to establish a stable cough baseline. Then 3-5 control pre-injection trials were
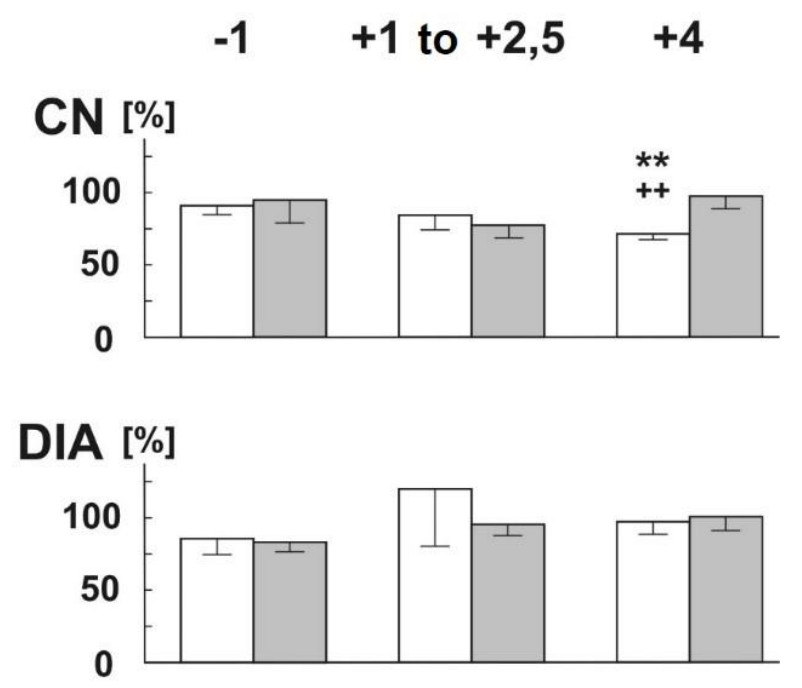

\section{ABD [\%]}
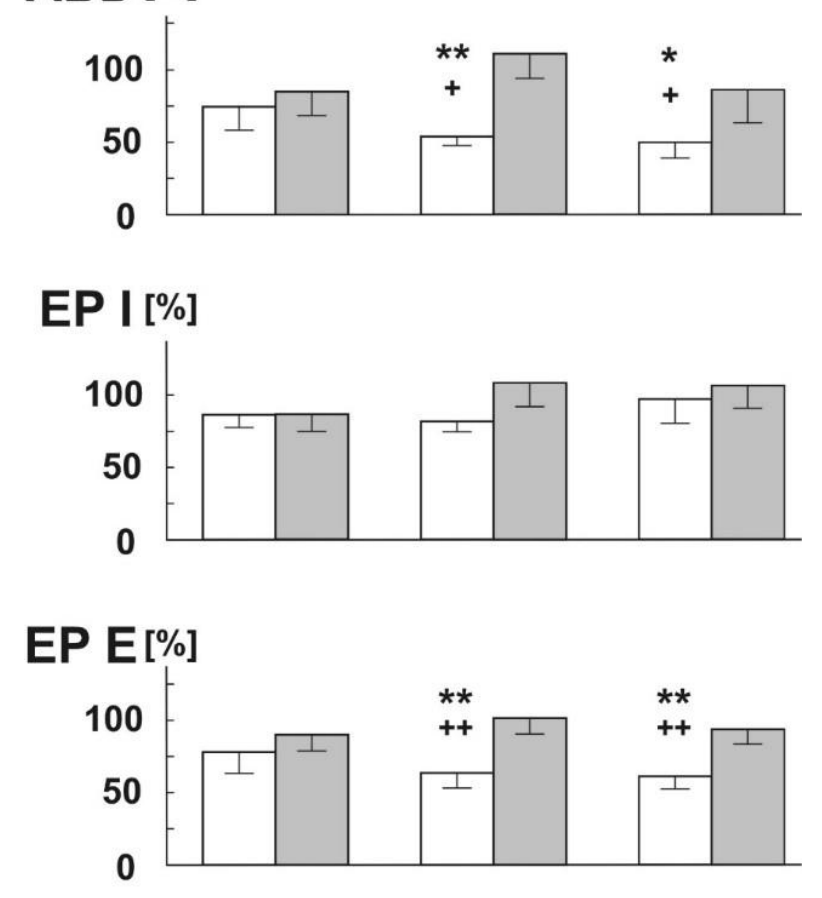

Fig. 3. Changes in tracheobronchial cough induced by microinjections of GABA into medullary raphé. Open bars represent percentages of control $(100 \%)$ within 5 min postmicroinjection interval, gray bars represent recovery data. $-1-$ microinjections approximately $1 \mathrm{~mm}$ caudal to obex, +1 to $+2,5$ - microinjections $1-2.5 \mathrm{~mm}$ rostral to obex, $+4-$ microinjections approximately $4 \mathrm{~mm}$ rostral to obex, $\mathrm{ABD}$ - abdominal muscles EMG amplitudes, CN - cough number, DIA - diaphragm EMG amplitudes, EP E - expiratory amplitudes of esophageal pressure, EP I - inspiratory amplitudes of esophageal pressure. $*, * *$ : $\mathrm{p}<0.05,0.01$ compared to the control data;,$+++: \mathrm{p}<0.05,0.01$ compared to the recovery data, respectively. 
made. Another sequence of trials was performed in the period $0-7 \mathrm{~min}$ after the microinjection (starting approximately $1 \mathrm{~min}$ after the last microinjection) followed by additional trials in the later post-injection intervals, usually at 20-40 min post-microinjections and more than 1 and 2 hours after microinjections. Exclusion criterion was if none of the parameters of CN, ABD EMG and expiratory EP amplitude did recover to at least $50 \%$ of difference between post-injection and pre-injection (control) value or if either $\mathrm{CN}$ or cough intensity had no tendency for returning towards control values.

Magnitudes of the moving averages during coughing were normalized relative to the mean intensities of control pre-injection coughs (the average magnitudes of all control coughs for each particular EMG). All parameters were averaged over each group of related 3-5 trials. After long intervals in the protocol, in which mechanical stimuli were not applied to the trachea (e.g. the recovery period) we often observed a reduced cough response during the first trial after this interval. We eliminated this cough trial from the analysis due to unstable and reduced coughing. This transient reduction in cough excitability after a delay or gap between tracheobronchial stimulation trials occurred regularly even in vehicle treated animals (Poliacek et al. 2010).

\section{Results}

In total, we performed 47 sequences of microinjections on 31 animals into medullary raphé area under 5 protocols. Caudal to the obex 5 GABA applications (6 microinjections in 3 locations - depths during 2 consecutive series of injections, in one case only 3 microinjections in total), in the locations 1-2.5 mm rostral to the obex we performed 9 GABA applications (6 microinjections in 3 locations - depths, in 2 animals the microinjections were conducted independently at both +1 and $+2.5 \mathrm{~mm}$ rostral to the obex and the average of these two was included in the analysis), in the area of the most rostral medulla we performed 7 GABA applications (6 microinjections in 3 locations - depths).

We performed 7 applications of muscimol and 7 applications of baclofen dorso-caudally (4 microinjections in 2 depths and 2 rostral positions) directed to the NRO. In rostro-ventral area, directed mainly to NRP and caudal NRM, 5 applications of muscimol and 7 baclofen applications were performed (4 microinjections in 2 depths and 2 rostral positions).

Single protocols were performed on 21 animals, multiple protocols on 10 animals (2 protocols on 5 animals, 3 protocols on 4 animals, and 4 protocols on 1 animal) with a 30-70 min time interval between the protocols (mainly muscimol and baclofen microinjections). Additional protocols were performed only if the animal had a full return to baseline conditions.

$G A B A$

The microinjections of $1 \mathrm{mM}$ GABA into the raphé caudally from the obex (total $214 \pm 49 \mathrm{nl}$ in 4 cats, $79 \mathrm{nl}$ total in 1 cat with 3 microinjections) did not cause any significant changes of the cough reflex (Fig. 3, temporal parameters were not analyzed).
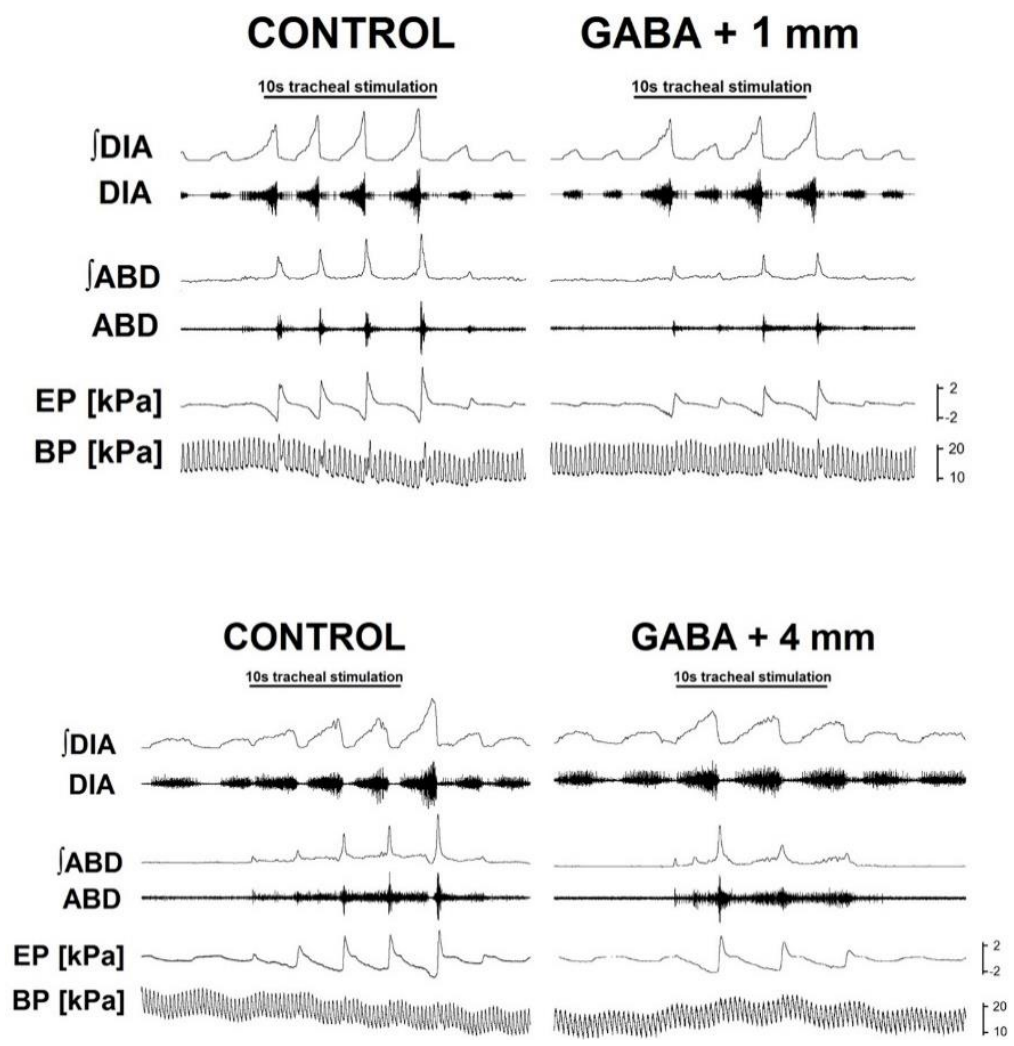

Fig. 4. Representative recordings of cough changes after GABA microinjections into medullary raphé. $\int$ - integrated activity, $A B D$ abdominal muscles EMG, BP - arterial blood pressure, DIA - diaphragm EMG, EP - esophageal pressure, GABA $+1 \mathrm{~mm}$ - recording after GABA microinjection into rostral to obex rapheal region, GABA +4 mm - recording after GABA microinjection into the most rostral rapheal region. 
The microinjections of $1 \mathrm{mM}$ GABA into the raphé rostral to the obex (total $194 \pm 23 \mathrm{nl}, 7$ cats) resulted in a significant decrease of the amplitudes of ABD EMG and expiratory EP during the cough reflex (Figs 3, 4). The time interval of recovery of the cough reflex varied (7-20 min, in one case $60 \mathrm{~min}$ ).

The microinjections of $1 \mathrm{mM}$ GABA into the medullary midline region $4 \mathrm{~mm}$ rostral to the obex (total $207 \pm 20 \mathrm{nl}, 7$ cats) resulted in a significant decrease of $\mathrm{CN}$ (ANOVA $p=0.003$ ) from $4.5 \pm 0.3$ to $3.2 \pm 0.2 \quad(p<0.01)$, with recovery to $4.4 \pm 0.5 \quad(p<0.01)$. There was also a significant decrease of ABD EMG amplitudes as well as a decrease of expiratory EP during the cough reflex (Figs 3, 4). The temporal analysis revealed a significant increase in CTI $1.46 \pm 0.19 \mathrm{~s} \quad(p<0.05$ to control $1.20 \pm 0.15 \mathrm{~s}$ and recovery $1.20 \pm 0.20 \mathrm{~s})$ and TDIA $1.95 \pm 0.27 \mathrm{~s}(p<0.05$ to control $1.59 \pm 0.20 \mathrm{~s}$ and recovery $1.64 \pm 0.27 \mathrm{~s}$ ) due to GABA microinjections (Fig. 4). The recovery of cough occurred 7-50 min after microinjections.

No significant changes in cardio-respiratory parameters after the GABA microinjections were seen (detailed data is not presented).

\section{Muscimol}

The microinjections of $0.5 \mathrm{mM}$ (in 2 cases $2 \mathrm{mM}$ ) muscimol (total $203 \pm 13 \mathrm{nl}, 0.18 \pm 0.02 \mathrm{nmol}$, 7 cats) in the dorso-caudal area caused a significant decrease of DIA and ABD EMG amplitudes, as well as of inspiratory and expiratory EP maxima during cough (Fig. 5, 6). The effect of the microinjections started slowly during minutes and lasted for $40 \mathrm{~min}$. Considering the suppression of cough within both the interval 0-7 min and 15-30 min after the microinjections, the post-injection data represents the average of results in these time intervals. The recovery of the cough reflex was seen $60-90 \mathrm{~min}$ (in 1 case $120 \mathrm{~min}$ ) after the muscimol application.

The microinjections of $0.5 \mathrm{mM}$ muscimol (in 2 cases $2 \mathrm{mM}$ ) into the rostro-ventral area (total $184 \pm 11 \mathrm{nl}, 0.19 \pm 0.03 \mathrm{nmol}, 5$ cats) did not cause any significant cough changes. The CTE1 phase shortened in the recovery time (detailed data is not presented).

No significant changes in cardio-respiratory characteristics were found after muscimol microinjections in the raphé areas (detailed data is not presented).

\section{Baclofen}

The microinjections of $1 \mathrm{mM}$ baclofen in the dorso-caudal area (total $158 \pm 7 \mathrm{nl}, 7$ cats) caused a significant decrease in $\mathrm{CN}$ (Figs 5, 6; ANOVA $p=0.038)$ from $8.70 \pm 2.83$ to $5.96 \pm 1.81 \quad(p<0.05)$ recovered to $7.49 \pm 1.94(p>0.05)$. The recovery occurred 20-40 min after the microinjections.

After the application of $1 \mathrm{mM}$ baclofen into the rostro-ventral area (total $171 \pm 18 \mathrm{nl}, 7$ cats) significant decreases in amplitudes of ABD EMG and expiratory EP during cough were found (Figs 5,6). The recovery time interval was 15-60 min.

No cardio-respiratory changes after the microinjections of baclofen were seen (detailed data is not presented).
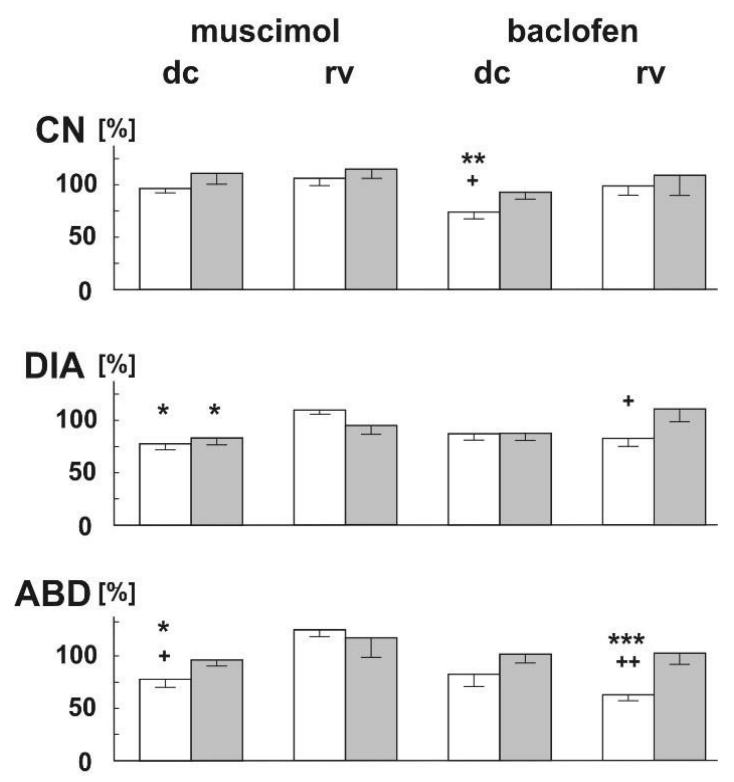

\section{EP | [\%]}
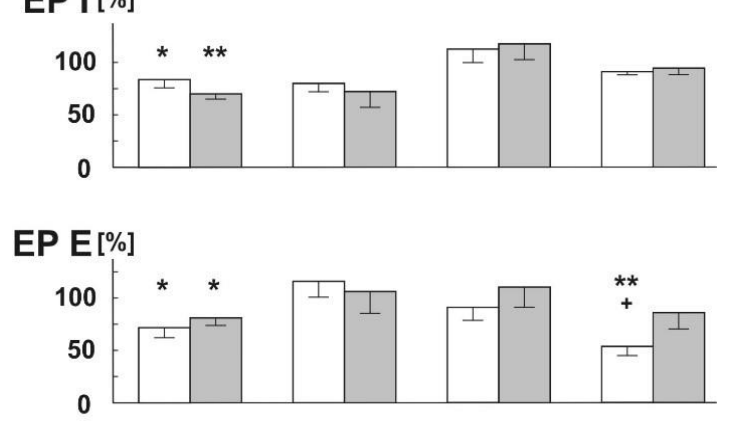

Fig. 5. Changes in tracheobronchial cough induced by microinjections of muscimol and baclofen into medullary raphé. Open bars represent percentages of control (100\%) within $30 \mathrm{~min}$ after microinjections of muscimol and $7 \mathrm{~min}$ after microinjection of baclofen, gray bars represent the recovery data. ABD - abdominal muscles EMG amplitudes, CN - cough number, dc - dorso-caudal rapheal region, DIA - diaphragm EMG amplitudes, EP E - expiratory esophageal pressure amplitudes, EP I - inspiratory esophageal pressure amplitudes, rv - rostroventral rapheal region. $*, * *, * * *: p<0.05,0.01,0.001$ compared to the control data; ${ }^{+},{ }^{++}: p<0.05,0.01$ compared to the recovery data, respectively. 


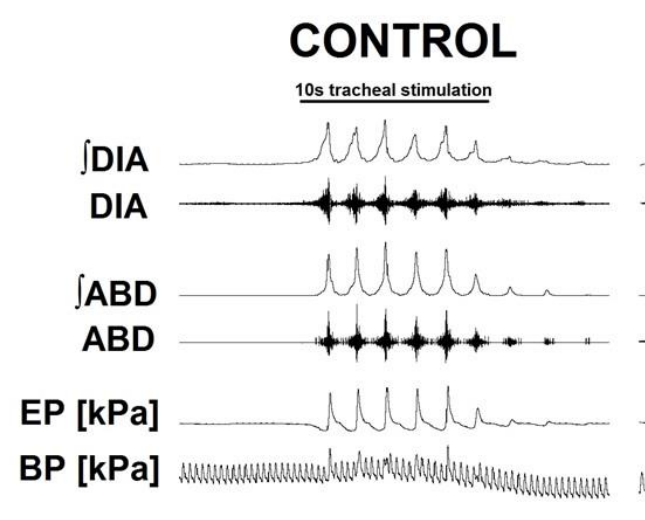

CONTROL

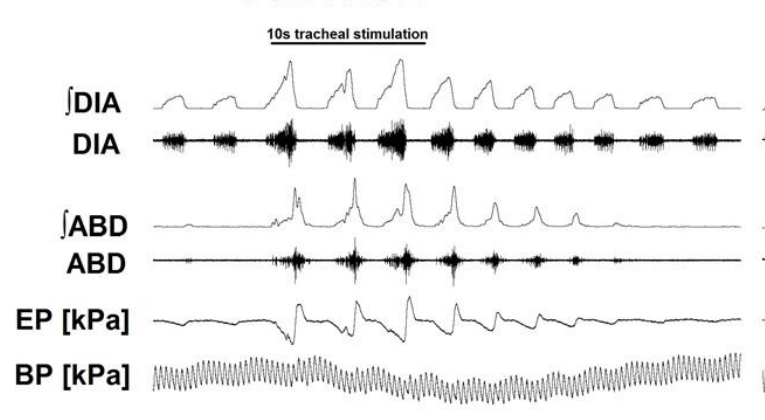

CONTROL

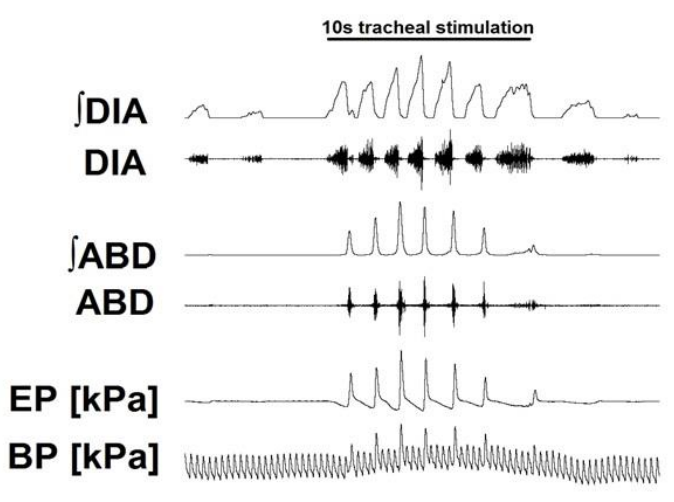

\section{Discussion}

This is the first study to examine the effects of GABA-ergic inhibition on medullary raphé neurons during mechanically induced tracheobronchial cough. Our results showed significant contribution of GABAergic neurotransmission on maximal cough motor drive with limited temporal changes. Additionally, the described changes were location and GABA A vs. B receptor subtype specific.

Distribution of GABA-ergic neurons in medullary raphé, which affect cough, have a strong, yet uneven, rostro-caudal distribution. GABA microinjections into raphé caudal to obex did not change cough. However, the most rostral location affected
Fig. 6. Representative recordings of cough reflex changes after microinjections of muscimol and baclofen into medullary raphé. $\int$ - integrated activity, ABD abdominal muscles EMG, BP - arterial blood pressure, DIA - diaphragm EMG, EP esophageal pressure, BACLOFEN $+1 \mathrm{~mm} \quad-$ recording after baclofen microinjection into dorsocaudal region, BACLOFEN $+4 \mathrm{~mm}$ - recording after baclofen microinjection into rostro-ventral region, MUSCIMOL $+1 \mathrm{~mm}-$ recording after muscimol microinjection into dorsocaudal region.

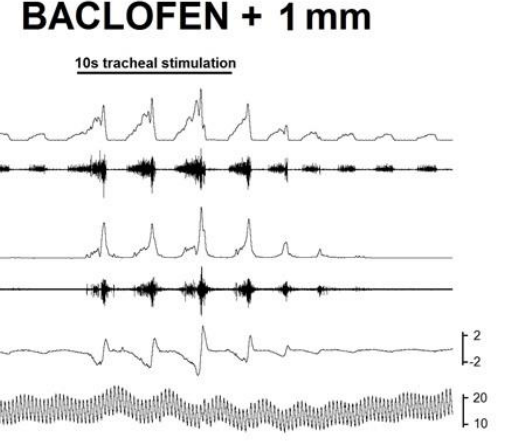

\section{BACLOFEN + $4 \mathrm{~mm}$}

10 s tracheal stimulation

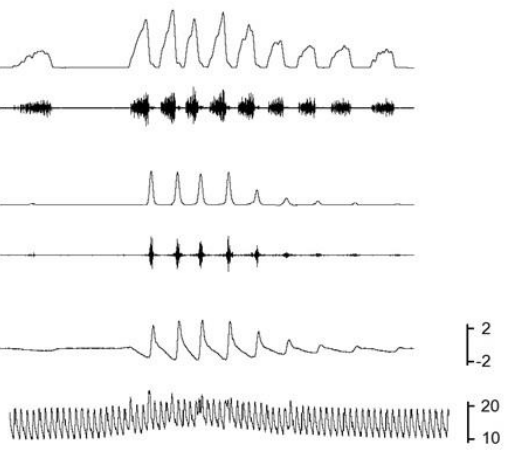


respiratory neuronal network (Budzinska and Romaniuk 1995, Lindsey et al. 1994). We presume that majority of effects caused by microinjections of GABA-ergic agents into the raphé were mediated by mutual interactions between rapheal and respiratory neuronal populations. Significant prolongation of cough related DIA activation and CTI when GABA was delivered to the most rostral location is consistent with this hypothesis. Of note, the cardiorespiratory characteristics did not change, which is a frequent finding in this preparation (Poliacek et al. 2010, 2012, 2017), even though, medullary raphé neurons strongly contribute to cardiorespiratory control (Jakus et al. 1998, Simera et al. 2013) and GABA-ergic inhibition is involved in this regulation (Aoki et al. 1995, Inyushkin et al. 2010, Taylor et al. 2006, Zaretsky et al. 2003).

Specific reduction in $\mathrm{CN}$ and expiratory efforts with no other alterations in cough motor pattern are typical for reduced drive from the functional cough control element termed cough gating (Bolser et al. 2006). Neurons participating in the cough gating mechanism can be inhibited by GABA, as well as central antitussives (i.e. codeine). Although codeine sensitive neurons are present in rostral raphé regions (Dias et al. 2012), we previously showed, that the application in the aforementioned location had no significant effects on cough (Poliacek et al. 2012). In conjunction with the present data, there is strong evidence that the GABA-ergic mechanism regulating cough in medullary raphé is distinct from cough gating.

Of note, due to the multiple microinjections executed during one procedure, we frequently observed fluorescent marker deposited along the pipette track. Thus, the analysis (Figs 1, 2) included area up to 0.4-0.5 mm from the pipette track (Lipski et al. 1988, Poliacek et al. 2017). The affected portions of medullary raphé and adjacent medial reticular formation were accounted for during analysis.

Our results show that $\mathrm{GABA}_{\mathrm{A}}$ and $\mathrm{GABA}_{\mathrm{B}}$ receptors specifically contribute to regulation of cough reflex in medullary raphé. We attempted to provide more spatial description by restricting microinjections of muscimol and baclofen compared with GABA. Our results demonstrated that similar to GABA application, muscimol dorso-caudally and baclofen rostro-ventrally decreased expiratory cough efforts. These findings indicate crucial involvement of $\mathrm{GABA}_{\mathrm{A}}$ receptors within rostral NRO, and $\mathrm{GABA}_{\mathrm{B}}$ receptors within the rostral NRP and caudal NRM for regulation of cough.

In contrast uneven effects of GABA, muscimol and baclofen microinjections (Figs 3-6) on cough were also observed in the rostro-ventral raphé and the dorsocaudal region. Unlike with GABA, no significant alterations in $\mathrm{CN}$ with either of specific GABA receptor analogs were seen in rostro-ventral raphé area. Vice versa, baclofen microinjections targeting dorso-caudal region resulted in mild, but significant reduction of $\mathrm{CN}$ (unlike GABA). To provide additional information, two additional animals were run with a mixture of baclofen and muscimol microinjected into all the dorso-ventral extensions of raphé. Under these conditions no $\mathrm{CN}$ reduction was being observed. We hypothesize that the different effects of GABA and baclofen may be due to: 1) unequal tissue volumes affected, or more likely, 2) baclofen having stronger, longer and more specific action on GABAB (Hupé et al. 1999), and/or 3) combining GABA receptor stimulation disrupts the modulation of specific receptors subtypes (Inyushkin et al. 2010). Moreover, contribution of local neuronal circuits and/or coordinated action with tuning inhibitory neurotransmission on serotoninergic as well as nonserotoninergic neurons in NRM might be involved in cough modulation (Lira et al. 2003, Inyushkin et al. 2010).

Finally, muscimol, in the dorso-caudal raphé, lead to moderate, but statistically significant decreases $(<30 \%)$ in inspiratory cough efforts (Fig. 5) with no recovery towards the control values. Possible effect of $\mathrm{GABA}_{\mathrm{A}}$ mediated active inhibition on cough inspiratory efforts in this region is contradictive with the results of GABA microinjections experiments. Possible differences in action of GABA and the analogs of GABA receptors (suggested earlier) either on cough-related rapheal interneurons or on neurons projecting directly to the phrenic nuclei (Holtman et al. 1984) may contribute to this effect.

\section{Conflict of Interest}

There is no conflict of interest.

\section{Acknowledgements}

This work was supported by VEGA 1/0072/16, VEGA 1/0166/17 and VEGA 1/0275/19. 


\section{References}

AOKI M, SATO Y, NAKAZONO Y, KOHAMA I: Effects of GABA receptor antagonists on the raphe magnusinduced inhibition of bulbar and spinal respiratory neural activities in the cat. Adv Exp Med Biol 393: 33-38, 1995. https://doi.org/10.1007/978-1-4615-1933-1_7

BAEKEY DM, MORRIS KF, NUDING SC, SEGERS LS, LINDSEY BG, SHANNON R: Medullary raphe neuron activity is altered during fictive cough in the decerebrate cat. J Appl Physiol 94: 93-100, 2003. https://doi.org/10.1152/japplphysiol.00341.2002

BERMAN AL: The Brain Stem of the Cat: A Cytoarchitectonic Atlas With Stereotaxic Coordinates. 1 ed. University of Wisconsin Press, Madison, Wisconsin, 1968.

BESNARD S, DENISE P, CAPPELIN B, DUTSCHMANN M, GESTREAU C: Stimulation of the rat medullary raphe nuclei induces differential responses in respiratory muscle activity. Respir Physiol Neurobiol 165: 208-214, 2009. https://doi.org/10.1016/j.resp.2008.12.004

BOLSER DC, DAVENPORT PW: Functional organization of the central cough generation mechanism. Pulm Pharmacol Ther 15: 221-225, 2002. https://doi.org/10.1006/pupt.2002.0361

BOLSER DC, POLIACEK I, JAKUS J, FULLER DD, DAVENPORT PW: Neurogenesis of cough, other airway defensive behaviors and breathing: A holarchical system? Respir Physiol Neurobiol 152: 255-265. 2006. https://doi.org/10.1016/j.resp.2006.01.008

BUDZINSKA K, ROMANIUK JR: The role of raphe and tractus solitarius neuronal structures in the modulation of respiratory pattern in rabbits. Acta Neurobiol Exp 55: 155-164, 1995.

DIAS MB, NUCCI TB, BRANCO LGS, GARGAGLIONI LH: Opioid $\mu$-receptors in the rostral medullary raphe modulate hypoxia-induced hyperpnea in unanesthetized rats. Acta Physiol 204: 435-442, 2012. https://doi.org/10.1111/j.1748-1716.2011.02345.x

HAXHIU MA, EROKWU B, BHARDWAJ V, DRESHAJ IA: The role of the medullary raphe nuclei in regulation of cholinergic outflow to the airways. J Auton Nerv Syst 69: 64-71, 1998. https://doi.org/10.1016/S0165$\underline{1838(98) 00009-5}$

HOLTMAN JR JR, NORMAN WP, GILLIS RA: Projections from the raphe nuclei to the phrenic motor nucleus in the cat. Neurosci Lett 44: 105-111, 1984. https://doi.org/10.1016/0304-3940(84)90229-5

HOLTMAN JR JR, ANASTASI NC, NORMAN WP, DRETCHEN KL: Effect of electrical and chemical stimulation of the raphe obscurus on phrenic nerve activity in the cat. Brain Res 362: 214-220, 1986. https://doi.org/10.1016/0006-8993(86)90446-4

HORNUNG JP: The human raphe nuclei and the serotonergic system. J Chem Neuroanat 26: 331-343, 2003. https://doi.org/10.1016/j.jchemneu.2003.10.002

HOSOGAI M, MATSUO S, NAKAO S: Firing pattern and location of respiratory neurons in cat medullary raphe nuclei. Neurosci Lett 161: 149-152, 1993. https://doi.org/10.1016/0304-3940(93)90281-O

HUPÉ JM, CHOUVET G, BULLIER J: Spatial and temporal parameters of cortical inactivation by GABA. J Neurosci Methods 86: 129-143, 1999. https://doi.org/10.1016/S0165-0270(98)00162-9

INYUSHKIN AN, MERKULOVA NA, ORLOVA AO, INYUSHKINA EM: Local GABAergic modulation of the activity of serotoninergic neurons in the nucleus raphe magnus. Neurosci Behav Physiol 40: 885-893, 2010. https://doi.org/10.1007/s11055-010-9337-x

JAKUS J, STRÁNSKY A, POLIACEK I, BARÁNI H, BOŠELOVÁ L': Effects of medullary midline lesions on cough and other airway reflexes in anaesthetized cat. Physiol Res 47: 203-213, 1998.

LALLEY PM: Responses of phrenic motoneurones of the cat to stimulation of medullary raphe nuclei. J Physiol 380 : 349-371, 1986. https://doi.org/10.1113/jphysiol.1986.sp016290

LINDSEY BG, HERNANDEZ YM, MORRIS KF, SHANNON R, GERSTEIN GL: Respiratory-related neural assemblies in the brain stem midline. J Neurophysiol 67: 905-922, 1992. https://doi.org/10.1152/jn.1992.67.4.905

LINDSEY BG, SEGERS LS, MORRIS KF, HERNANDEZ YM, SAPORTA S, SHANNON R: Distributed actions and dynamic associations in respiratory-related neuronal assemblies of the ventrolateral medulla and brain stem 
midline: evidence from spike train analysis. J Neurophysiol 72: 1830-1851, 1994. https://doi.org/10.1152/jn.1994.72.4.1830

LINDSEY BG, MORRIS KF, SEGERS LS, SHANNON R: Respiratory neuronal assemblies. Respir Physiol 122: 183196, 2000. https://doi.org/10.1016/S0034-5687(00)00158-4

LIPSKI J, BELLINGHAM MC, WEST MJ, PILOWSKI P: Limitations of the technique of pressure microinjection of excitatory a mino acids for evoking responses from localized regions of the CNS. J Neurosci Methods 26: 169179, 1988. https://doi.org/10.1016/0165-0270(88)90166-5

LIRA A, ZHOU M, CASTANON N, ANSORGE MS, GORDON JA, FRANCIS JH, BRADLEY-MOORE M, LIRA J, UNDERWOOD MD, ARANGO V, KUNG HF, HOFER MA, HEN R, GINGRICH JA: Altered depressionrelated behaviors and functional changes in the dorsal raphe nucleus of serotonin transporter-deficient mice. Biol Psychiatry 54: 960-971, 2003. https://doi.org/10.1016/S0006-3223(03)00696-6

MILLER AD, NONAKA S, JAKUS J, YATES BJ: Modulation of vomiting by the medullary midline. Brain Res 737 : 51-58, 1996. https://doi.org/10.1016/0006-8993(96)00663-4

MILLHORN DE: Stimulation of raphe (obscurus) nucleus causes long-term potentiation of phrenic nerve activity in cat. J Physiol 381: 169-179, 1986. https://doi.org/10.1113/jphysiol.1986.sp016320

POLIACEK I, WANG C, CORRIE LW-C, ROSE MJ, BOLSER DC: Microinjection of codeine into the region of the caudal ventral respiratory column suppresses cough in anesthetized cats. J Appl Physiol 108: 858-865, 2010. https://doi.org/10.1152/japplphysiol.00783.2009

POLIACEK I, SIMERA M, VETERNIK M, MACHAC P, BARANI H, VISNOVCOVA N, HALASOVA E, JAKUS J: Contribution of medullary raphé to control of coughing - codeine trials in cat. Respir Physiol Neurobiol 184: 106-112, 2012. https://doi.org/10.1016/j.resp.2012.08.010

POLIACEK I, JAKUS J, SIMERA M, VETERNIK M, PLEVKOVA J: Control of coughing by medullary raphé. Prog Brain Res 212: 277-295, 2014. https://doi.org/10.1016/B978-0-444-63488-7.00014-8

POLIACEK I, SIMERA M, VETERNIK M, KOTMANOVA Z, PITTS T, HANACEK J, PLEVKOVA J, MACHAC P, VISNOVCOVA N, MISEK J, JAKUS $\mathrm{J}$ : The course of lung inflation alters the central pattern of tracheobronchial cough in cat - The evidence for volume feedback during cough. Respir Physiol Neurobiol 229: 43-50. 2016. https://doi.org/10.1016/j.resp.2016.04.008

POLIACEK I, SIMERA M, VETERNIK M, KOTMANOVA Z, BOLSER DC, MACHAC P, JAKUS J: Role of the dorsomedial medulla in suppression of cough by codeine in cats. Respir Physiol Neurobiol 246: 59-66, 2017. https://doi.org/10.1016/j.resp.2017.07.011

PRITCHARD TC, ALLOWAY KD: Medical Neuroscience. Fence Creek Pub 1999, 451 p.

PTAK K, YAMANISHI T, AUNGST J, MILESCU LS, ZHANG R, RICHERSON GB, SMITH JC: Raphé neurons stimulate respiratory circuit activity by multiple mechanisms via endogenously released serotonin and substance P. J Neurosci 29: 3720-3737, 2009. https://doi.org/10.1523/JNEUROSCI.5271-08.2009

SESSLE BJ, BALL GJ, LUCIER GE: Suppressive influences from periaqueductal gray and nucleus raphe magnus on respiration and related reflex activities and on solitary tract neurons, and effects of naloxone. Brain Res 216 : 145-161, 1981. https://doi.org/10.1016/0006-8993(81)91283-X

SHANNON R, BAEKEY DM, MORRIS KF, NUDING SC, SEGERS LS, LINDSEY BG: Production of reflex cough by brainstem respiratory networks. Pulm Pharmacol Ther 17: 369-376, 2004. https://doi.org/10.1016/j.pupt.2004.09.022

SIMERA M, POLIACEK I, VETERNIK M, DOBROLUBOV B, CIBULKA M, BARANI H, VISNOVCOVA N, JAKUS J: Differential effects of kainic acid lesions in medullary raphe on cough and sneeze in anesthetized rabbits. Adv Exp Med Biol. 788: 39-45, 2013. https://doi.org/10.1007/978-94-007-6627-3 6

TABER E, BRODAL A, WALBERG F: The raphe nuclei of the brain stem in the cat. I. Normal topography and cytoarchitecture and general discussion. J Comp Neurol 114: 161-187, 1960. https://doi.org/10.1002/cne.901140205

TAYLOR NC, LI A, NATTIE EE. Ventilatory effects of muscimol microdialysis into the rostral medullary raphé region of conscious rats. Respir Physiol Neurobiol 153: 203-216, 2006. https://doi.org/10.1016/j.resp.2005.11.005 
VETERNIK M, SIMERA M, JAKUS J, POLIACEK I: Integration of simulated multipotential signals: the role of integration window width and of the number of spikes. Adv Exp Med Biol 788: 265-272, 2013. https://doi.org/10.1007/978-94-007-6627-3_37

ZARETSKY DV, ZARETSKAIA MV, DIMICCO JA: Stimulation and blockade of GABA(A) receptors in the raphe pallidus: effects on body temperature, heart rate, and blood pressure in conscious rats. Am J Physiol Regul Integr Comp Physiol 285: R110-R116, 2003. https://doi.org/10.1152/ajpregu.00016.2003 